ORIGINAL ARTICLE

\title{
Influence of disturbance and nutrient enrichment on early successional fouling communities in an oligotrophic marine system
}

\author{
João Canning-Clode ${ }^{1,2}$, Manfred Kaufmann², Markus Molis ${ }^{3}$, Martin Wahl ${ }^{1}$ \& Mark Lenz ${ }^{1}$ \\ 1 Leibniz Institute of Marine Sciences, University of Kiel, Kiel, Germany \\ 2 Department of Biology \& Centre of Macaronesian Studies, University of Madeira, Funchal, Madeira Island, Portugal \\ 3 Biologische Anstalt Helgoland, Foundation Alfred-Wegener-Institute for Polar and Marine Research, Kurpromenade, Helgoland
}

\section{Keywords}

Disturbance; diversity; fouling; Madeira Island; multiple stressors; nutrient enrichment; productivity.

\section{Correspondence}

João Canning-Clode, Leibniz Institute of Marine Sciences, University of Kiel, Duesternbrooker Weg 20, 24105 Kiel, Germany.

E-mail: jcanning-clode@ifm-geomar.de

Accepted: 12 November 2007

doi:10.1111/j.1439-0485.2007.00210.x

\begin{abstract}
Disturbance and productivity are often cited as the main factors determining temporal and spatial patterns in species distribution and the diversity of communities. A field experiment was conducted to test the role of these factors in the structuring of early successional fouling communities in a nutrient limited system at the south coast of Madeira Island. Macro-benthic sessile communities, established on artificial settlement substrata, were manipulated and surveyed over a 9-week period. We applied mechanical disturbances of four different frequencies crossed with three levels of inorganic nutrient enrichment. Fertilization enhanced community diversity by favouring the establishment and growth of macroalgae. Disturbance reduced diversity by eliminating species but only at the highest nutrient level. This is explained by a multiple-stressor model; species most sensitive to nutrient deficiency (only present in the highest enrichment treatment) were simultaneously the most sensitive to disturbance.
\end{abstract}

\section{Problem}

Since several decades, most ecosystems experience a rapid loss of biodiversity (e.g. Hooper et al. 2005). This process is observable at both local and global spatial scales, and at organisational levels from genomes to landscapes (Sala \& Knowlton 2006). While the ongoing loss of biodiversity is not questioned, the significance of the loss, i.e. the ecological role of diversity, was debated for years. Meanwhile, apart from ethical considerations, the value of taxonomic and functional diversity for ecosystem services and community stability is postulated theoretically and frequently found experimentally (e.g. Loreau et al. 2001; Giller et al. 2004; Balvanera et al. 2006). The heterogeneous distribution of diversity at different scales in space and in time has incited the formulation of explanatory models over the last decades (Connell 1978; Huston 1994; Hubbell 2001). Two factors which have frequently been suggested to control diversity, are disturbance (Connell 1978; Sousa
1979) and system productivity (Huston 1979; Berendse 1993). Disturbance is considered a relatively discrete event in time that removes biomass, liberates resources, interrupts succession and facilitates the establishment of new individuals (from Grime 1977; Sousa 1984; White \& Pickett 1985). 'Productivity' is a somewhat vaguer concept, which alternately has been used in the sense of annual primary production, site fertility, larval settlement rate, or nutrient availability (e.g. Menge \& Sutherland 1987; Berendse 1993; Allcock \& Hik 2003; Gessner et al. 2004). The most widely accepted model linking disturbance and diversity, as formulated in the Intermediate Disturbance Hypothesis (IDH, Connell 1978), postulates a unimodal relationship with maximum diversity at 'intermediate' levels of disturbance. Such a pattern is, however, only one of a variety of diversity-disturbance relationships found in nature (Mackey \& Currie 2001). The relationship between productivity and diversity seems to be similarly complex and variable (Waide et al. 1999; Mittelbach et al. 
2001; Chase \& Leibold 2002). It tends to be unimodal at a local and positively linear at a regional scale (e.g. Chase \& Leibold 2002). This inconsistency has been attributed to the influence of consumers, niche specialization, disturbance and spatial scale, which alter the influence of productivity on diversity with regard to different taxonomic groups and habitats (Fukami \& Morin 2003). Recent research suggests that productivity-richness relationships are scale-dependent and that species turnover, i.e. spatial and temporal variation in species composition, plays a key role in generating this dependence (Chase et al. 2000; Chase \& Leibold 2002; Chalcraft et al. 2004). Recently, Chase \& Leibold (2002) provided evidence for a scale-dependence productivity-biodiversity relationship in ponds. They characterized an individual pond as the local scale and a watershed as the regional scale. The authors found a 'hump-shaped' relationship at a local scale and a positive monotonic relationship at a regional scale. The scale dependence was attributed to dissimilarities in local species composition between areas of increasing productivity (Chase \& Leibold 2002). Some of the seemingly conflicting relational patterns between diversity, disturbance and productivity may be explained by interactive effects of disturbance and productivity on diversity (Kondoh 2001) and/or by the bi-directionality of the causality between diversity and productivity or between diversity and stability (the inverse of disturbance) (Worm \& Duffy 2003).

Models describing the interactive effects of disturbance and productivity on diversity were proposed by Huston (1994) and later by Proulx \& Mazumder (1998) and Kondoh (2001). According to these models, maximum diversity shifts to higher levels of disturbance when the productivity of the system is increased because of the opposing effects of productivity and disturbance; at higher productivity, superior competitors grow faster and higher disturbance levels are required to inhibit competitive exclusion. Conversely, at low productivity and slow growth rates, even moderate disturbances may maintain the community in an early successional and opportunist state. Kondoh (2001) postulates that a positive linear disturbance-diversity relationship should emerge when a system is highly productive, a unimodal relationship should be observed when productivity is moderate and a negative linear relationship when productivity is low. The bi-directionality model shows that while disturbance does affect diversity, species richness and composition (two aspects of diversity) affect community stability and thus modulate the effects of disturbance. Similarly, diversity may enhance productivity at a given site fertility, while the latter may enhance diversity at a regional scale, but reduce it at a local scale (Worm \& Duffy 2003; Gessner et al. 2004).
The present study was part of a modular global experiment assessing the interactive effects of disturbance and productivity in fouling assemblages at biogeographically different sites. Disturbance (biomass removal) and site fertility (i.e. availability of nutrients) were manipulated in a controlled manner. To date, the results of two of the subproject are published. The two studies, performed in Brazil (Jara et al. 2006) and Sweden (Svensson et al. 2007) reported maximum diversity at intermediate levels of disturbance, but only the study performed by Jara et al. (2006) found an interactive effect between disturbance and productivity on species richness.

This study was conducted in a nutrient limited, marine system at the south-coast of Madeira Island, Portugal. Here, we hypothesized that the influence of disturbance would vary among nutrient levels, i.e. that the disturbance frequency producing highest diversity would increase with nutrient level.

\section{Study Area}

The experiment was conducted in the Bay of Funchal, located at the south-coast of Madeira Island, Portugal. The experimental site $\left(32^{\circ} 38.7^{\prime} \mathrm{N}, 16^{\circ} 53.2^{\prime} \mathrm{W}\right)$ is situated inside the 'Garajau Nature Reserve'. It is characterized by an exposed rocky shore and serves as a fish nursery. Local tides are semidiurnal with a mean tidal range of approximately $2 \mathrm{~m}$. In this sea area, pelagic primary production is low with sea-surface chlorophyll concentrations of $0.07 \mathrm{mg} \cdot \mathrm{l}^{-1}$ (Caldeira et al. 2002), which are typical values for oligotrophic oceanic waters (Lalli \& Parsons 1997).

\section{Material and Methods}

\section{Experimental design and setup}

A total of 12 moorings with a minimum distance of $5 \mathrm{~m}$ between them were installed at our study site. Each mooring consisted of a ground weight and a buoy that held a ring (i.e. experimental block) made from stripes of grey polyvinylchloride $(\mathrm{PVC}, 2100 \times 250 \times 4 \mathrm{~mm})$ at a water depth of approximately $0.5 \mathrm{~m}$. PVC panels $(150 \times 150 \mathrm{~mm})$, roughened with grade 60 emery paper, were used as artificial settlement substrata and represented the experimental units. Ten of these tiles were fixed vertically to the inside of each PVC ring in a reversible manner and six of them were used for the experiment (Fig. 1).

Dynamics of macrobenthic sessile communities were examined under different nutrient and disturbance regimes in a 3-factorial experiment with the factors nutrient availability ( $\mathrm{N}$, fixed, three levels), block (B, random, four levels and nested with $\mathrm{N}$ ) and disturbance 


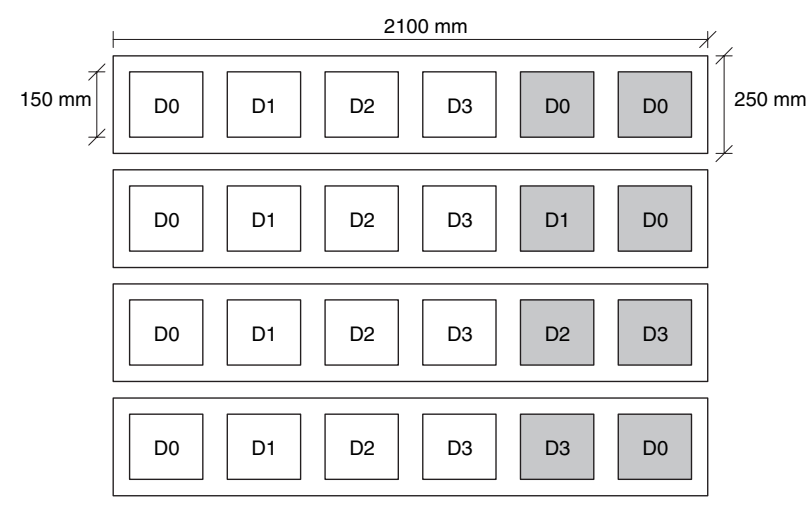

Fig. 1. Arrangement of settlement panels along the PVC stripes that were folded to rings (i.e. experimental blocks). Codes indicate levels of 'disturbance frequency'. The four blocks shown were nested in one level of 'nutrient availability'. Replication of disturbance levels within blocks (in grey) was identical across all levels of 'nutrient availability'. D0 $=$ controls (no disturbance); D1 = disturbed once after 8 weeks; D2 = disturbed every 4 weeks; D3 = disturbed every 2 weeks.

frequency (D, fixed, four levels and orthogonal to $\mathrm{N}$ and $\mathrm{B}$ ). To replicate at the block level, we had an extra panel for each of two randomly chosen disturbance treatments per ring (Underwood 1997), so that the total number of settlement tiles per block was 6 (Fig. 1). Because of the random selection of these within-block replicates, the levels of 'disturbance frequency' were replicated at different rates: we had eight replicates for the undisturbed controls, six replicates for disturbance frequency level 3 (disturbed every second week) and five replicates for disturbance frequency levels 1 and 2 (disturbed every eighth and fourth week, respectively, Fig. 1).

Prior to manipulation, settlement panels were exposed to natural colonisation for 9 weeks (March-May 2004). We ran the field experiment for another 9 weeks from May to July 2004. At the end of the colonisation phase, communities on two randomly chosen panels per ring were sampled non-destructively to obtain information about community composition and diversity at the start of the experiment. After this initial sampling, nutrients were manipulated and disturbance was applied over 9 weeks. At the end of the experiment, all panels were collected and sampled.

\section{Nutrient enrichment}

Nutrients in the water body around the settlement tiles were enriched by attaching ten mesh bags (2-mm mesh size) filled with coated controlled-release fertilizer in each experimental block. Bags were distributed evenly on the inside of the rings by placing them in the middle between neighbouring panels. Because of the impracticality of realizing different nutrient regimes within a single experi- mental block, we assigned each level of nutrient enrichment randomly to four of the 12 rings. For the controls (level 0, i.e. natural concentrations), each mesh bag was filled with $180 \mathrm{~g}$ of inert material (gravel). For enrichment level 1, we used $90 \mathrm{~g}$ of fertilizer and $90 \mathrm{~g}$ of gravel per pocket. For level 2, $180 \mathrm{~g}$ of fertilizer were put in each bag. Filling the pouches with equal amounts of material in all enrichment levels served to avoid experimental artefacts given by heterogeneous hydrodynamic conditions, which would have been created by bags of unequal volume.

The quantities of fertilizer used for the nutrient treatments were determined in a pilot study, which was conducted in February 2004 in the Bay of Funchal. We exposed mesh bags with 50, 100 and $200 \mathrm{~g}$ of fertilizer $(\mathrm{n}=4)$ for 1 week, and then took water samples at distances of $0,5,10$ and $40 \mathrm{~cm}$ away from each nutrient source. To determine ambient nutrient levels (control), further samples were taken at different points at least $500 \mathrm{~cm}$ from the fertilizer source. To assess fertilizer release rates, we analysed macronutrient concentrations near the four $200 \mathrm{~g}$ bags after 7, 14, 21, 28 and 35 days of their first exposure.

The coated controlled-release fertilizer Plantacote ${ }^{\circledR}$ pluss 6M (Aglukon) was used, because of its steady release rates in relation to its weight, i.e. doubling the amount of granulate results in an $100 \%$ increase in released ions (Worm et al. 2000). Before deployment, the fertilizer was soaked in containers with seawater for 5 days to ensure that nutrients were released from the first day of exposure. During the experiment, the fertilizer in the bags was replaced once at mid-term. To check whether nutrient enrichment provoked higher plankton concentration at the small scale of a ring, every second week we took $500 \mathrm{ml}$ of water from the inside of each ring with a plastic container, filtered it through Whatman GF/F-filters and froze the filters at $-25{ }^{\circ} \mathrm{C}$ for later chlorophyll $a$ analysis using the methods of Jeffrey \& Humphrey (1975). Nitrite, nitrate, and phosphate concentrations were quantified within 3 weeks after sampling, following the methods of Grasshoff et al. (1999).

\section{Disturbance treatments}

According to the definition of disturbance given by Grime (1977), we removed a fixed amount of biomass from each experimental unit per disturbance event. All organisms were, therefore scraped from two randomly selected circular spots, each representing $10 \%$ of the total panel area. Four different levels of disturbance frequency were realized by disturbing the panels every second, fourth and eighth week and by leaving them undisturbed throughout the experimental phase. Hereafter these levels are labelled 
as 3, 2, 1 and 0 respectively. Disturbances were applied in situ by snorkeling.

\section{Community structure sampling}

For sampling of community variables, before and after manipulation, the rings were brought to the shore and the settlement panels were detached. During this operation, care was taken that the encrusting assemblages were submerged in seawater and protected from direct sun light.

We estimated community composition by measuring percent cover of all sessile species $>1 \mathrm{~mm}$ in size in steps of $5 \%$. To facilitate this, we employed a $15 \times 15 \mathrm{~cm}$ grid from plastic wire that was laid over the settlement tiles. A 1-cm wide margin at all sides of the panels was ignored to avoid edge effects. Total percent cover exceeded 100\% in case of multi-strata growth.

\section{Data analysis}

After the pilot study, nutrient enrichment effects of the differently loaded bags were tested by a one way ANOVA. In case of a significant effect, the Bonferroni test identified which dosages differed in their efficiency in enriching ambient seawater.

Pielou's evenness $\left(\mathrm{J}^{\prime}\right)$ and the Simpson index (D) were calculated from the obtained abundance data (Magurran 1988) and tested for normality. Total percent cover data were in all cases transformed (arcsine of the square root) prior to any further analysis (Underwood 1997; Benedetti-Cecchi 2004).

Two different statistical approaches were employed for the analyses of univariate data in this study. We tested for a linear or a unimodal relationship between disturbance frequency and species richness, evenness and Simpson index, with simple linear or quasilinear regression at each nutrient level separately. Additionally, we performed a three-way nested ANOVA to identify interactions between the two fixed factors 'disturbance frequency' and 'nutrient availability'. This was performed in a two step procedure: first we calculated the sums of squares for all sources of variation despite the error term using the four replicates of non-identical treatments present in each block. In a second step, we re-ran this analysis and included only the replicates belonging to treatments that were replicated within the blocks, which provided the sums of squares for the error term. On the basis of this we calculated the mean squares and F-ratios according to the information given in Table 1. Homogeneity of variances for significant effects was tested with Cochran's Ctest and multiple comparisons (Tukey's HSD) identified significant differences between treatment levels.

\section{Results}

Effects of fertilizer deployment on concentrations of dissolved phosphate and nitrate near the settlement panels

The distance between the centre of the settlement panels and the mesh bags filled with fertilizer granulate in the set-up used for the main experiment was $7.5 \mathrm{~cm}$. Therefore, we used the values obtained in the pilot study at a distance of $5 \mathrm{~cm}$ from the nutrient source to determine the fertilizer quantities for the different nutrient availability levels in the main experiment.

The chosen Plantacote ${ }^{\circledR}$ fertilizer increased nutrient availability in close proximity to the bags fixed between the settlement panels in the main experiment. In the pilot study, mean concentrations of dissolved phosphate, at a distance of approximately $5 \mathrm{~cm}$ from the source, increased with the amount of fertilizer deployed (Fig. 2a). Phosphate concentrations near the bags with $200 \mathrm{~g}$ of granulate were significantly higher than near the controls (ANOVA: $\mathrm{F}=8.73 ; \mathrm{P}=0.0038 ;$ Bonferroni test; $\mathrm{P} \leq 0.05)$. Average nitrate concentration at $5 \mathrm{~cm}$ distance from the source also increased with increasing fertilizer supply (Fig. 2b), but ANOVA did not detect significant differences between dosages (Fig. 2b; one way ANOVA: $\mathrm{F}=2.58$; $\mathrm{P}>0.05$ ). Additionally, at a distance of $10 \mathrm{~cm}$ from the bags, mean concentrations of phosphate and nitrate ions were still different from ambient concentrations, while concentrations of the same nutrients at $40 \mathrm{~cm}$ from the bags were already similar to the controls. This suggests that fertilizer effects should be restricted to the direct proximity of the source. Moreover, after 35 days, phosphate and nitrate concentrations were decreased by approximately $40 \%$ and $80 \%$,

\begin{tabular}{lllll}
\hline Source of variation & Abbreviation & Effect & df & F-ratio \\
\hline Nutrient availability & $\mathrm{N}$ & fixed & 2 & $\mathrm{MS}_{\mathrm{N}} / \mathrm{MS}_{\mathrm{B}(\mathrm{N})}$ \\
Block (nutrient availability) & $\mathrm{B}(\mathrm{N})$ & random & 9 & $\mathrm{MS}_{\mathrm{B}(\mathrm{N})} / \mathrm{MS}_{\text {residuals }}$ \\
Disturbance & $\mathrm{D}$ & fixed & 3 & $\mathrm{MS}_{\mathrm{D}} / \mathrm{MS}_{\mathrm{D} \times \mathrm{B}(\mathrm{N})}$ \\
Nutrient availability $\times$ disturbance & $\mathrm{N} \times \mathrm{D}$ & fixed & 6 & $\mathrm{MS}_{\mathrm{D} \times \mathrm{N}} / \mathrm{MS}_{\mathrm{D} \times \mathrm{B}(\mathrm{N})}$ \\
Disturbance $\times$ block (nutrient availability) & $\mathrm{D} \times \mathrm{B}(\mathrm{N})$ & random & 27 & $\mathrm{MS}_{\mathrm{D} \times \mathrm{B}(\mathrm{N})} / \mathrm{MS}_{\text {residuals }}$ \\
Residuals & & & 20 & \\
\hline
\end{tabular}

Table 1. Degrees of freedom (df) and description of the calculation of the F-ratio.

MS, mean squares. 

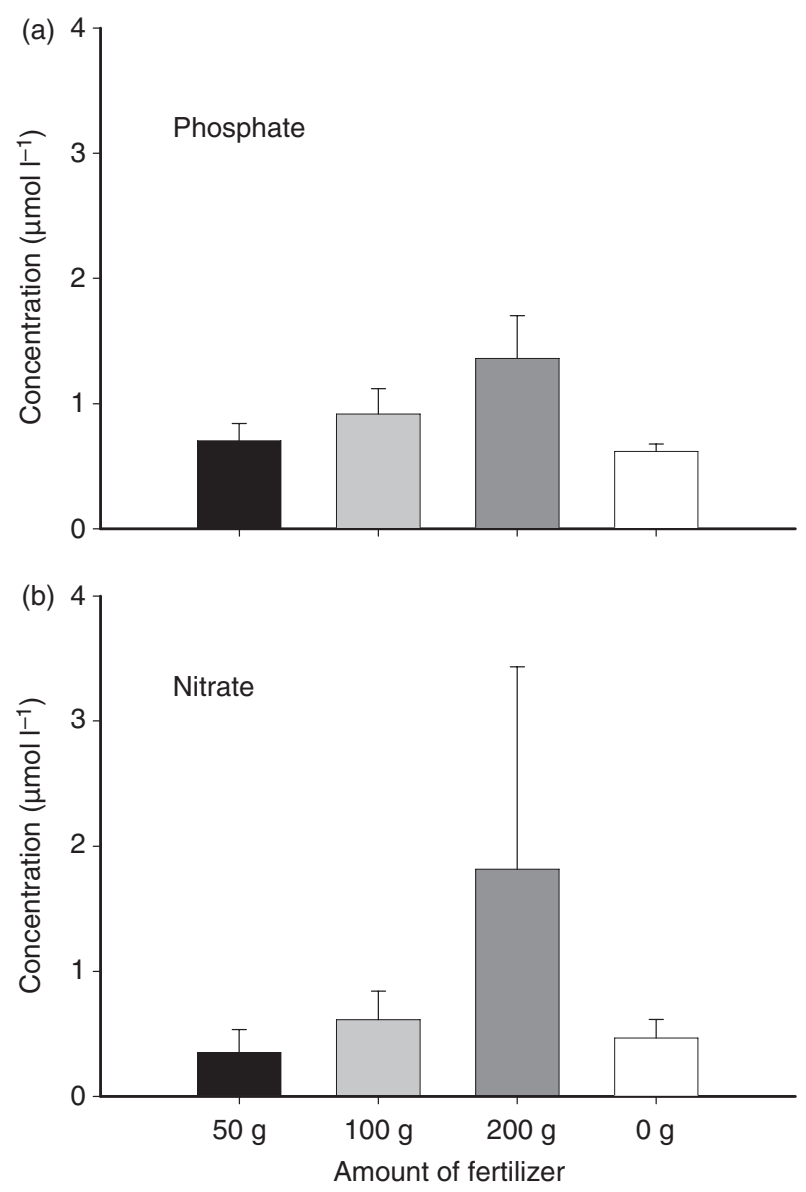

Fig. 2. Concentrations of dissolved (a) phosphate and (b) nitrate at approximately $5 \mathrm{~cm}$ from different quantities of Plantacote ${ }^{\circledR}$ fertilizer: $50 \mathrm{~g}$ (black), $100 \mathrm{~g}$ (light grey), $200 \mathrm{~g}$ (dark grey) and $0 \mathrm{~g}$ (white). Bar $=$ mean, whisker $=$ standard deviation, $n=4$.

respectively, when compared to the previous measurements made after 28 days. For this reason, we renewed all fertilizer doses after 30 days during the course of the study.

Analyses of water samples during the experimental period from May to July 2004 failed to quantify fertilizer release rates reliably. The large variability may have been because of water movement. The measured nutrient concentrations varied among blocks on average between 0.1 and $0.4 \mu \mathrm{mol} \cdot l^{-1}$ for nitrite, 2.7 and $6.6 \mu \mathrm{mol} \cdot l^{-1}$ for nitrate, and 1.0 and $3.0 \mu \mathrm{mol} \cdot \mathrm{l}^{-1}$ for phosphate. Nutrient availability levels are in the following referred to as ambient, enriched ${ }^{+}$and enriched ${ }^{++}$. The content of chlorophyll $a$ in the water column was below the detection limit of $0.2 \mathrm{mg} \cdot \mathrm{l}^{-1}$ at sampling dates.

\section{Fouling community composition}

Eighteen weeks after the start of the experiment, including 9 weeks of manipulation, a total of 16 macroalgae
Table 2. List of sessile species observed on the settlement panels after 9 weeks of succession followed by 9 weeks of experimental manipulation.

\begin{tabular}{|c|c|}
\hline & abundance after 9 weeks \\
\hline \multicolumn{2}{|l|}{ algae } \\
\hline \multicolumn{2}{|l|}{ Chlorophyta } \\
\hline Bryopsis sp. & - \\
\hline Chaetomorpha sp. & - \\
\hline Codium adherens & - \\
\hline Enteromorpha intestinalis & - \\
\hline Ulva rigida & + \\
\hline \multicolumn{2}{|l|}{ Heterokontophyta } \\
\hline Colpomenia sinuosa & - \\
\hline Licmophora sp. & - \\
\hline class Bacillariophyceae: species 1 & + \\
\hline \multicolumn{2}{|l|}{ Rhodophyta } \\
\hline Ceramium sp. & + \\
\hline Champia parvula & + \\
\hline Corallina sp. & - \\
\hline Jania sp. & + \\
\hline Laurencia sp. & + \\
\hline Lithophyllum incrustans & ++ \\
\hline Polysiphonia sp. & ++ \\
\hline order Ceramiales: species 1 & - \\
\hline \multicolumn{2}{|l|}{ macroinvertebrates } \\
\hline \multicolumn{2}{|l|}{ Porifera } \\
\hline Class Calcarea: species 1 & - \\
\hline Class Calcarea: species 2 & - \\
\hline \multicolumn{2}{|l|}{ Cnidaria } \\
\hline Aglaophenia pluma & + \\
\hline Antennella sp. & - \\
\hline Obelia geniculata & - \\
\hline Pennaria disticha & + \\
\hline Tubularia larynx & - \\
\hline \multicolumn{2}{|l|}{ Annelida } \\
\hline Serpula vermicularis & + \\
\hline family Serpulidae: species 1 & - \\
\hline family Serpulidae: species 2 & - \\
\hline family Serpulidae: species 3 & - \\
\hline \multicolumn{2}{|l|}{ Arthropoda } \\
\hline Balanus sp. & + \\
\hline Lepas anatifera & - \\
\hline \multicolumn{2}{|l|}{ Bryozoa } \\
\hline family Lichenoporidae & - \\
\hline \multicolumn{2}{|l|}{ Chordata/Tunicata } \\
\hline Botryllus schlosseri & - \\
\hline Diplosoma sp. & ++ \\
\hline
\end{tabular}

Mean abundances are ranked as follows: $-=<1 \%$ cover, $+=1-10 \%$ cover, $++=>10 \%$ cover.

and 16 macroinvertebrates were found on the settlement panels (Table 2). The assemblages were dominated (mean cover $\geq 10 \%$ ) by the red algae Lithophyllum incrustans and Polysiphonia sp. and by the ascidian Diplosoma sp. Species like the red algae Ceramium sp. and Champia parvula and the hydrozoan Pennaria disticha were present, but less abundant (mean cover $=1-10 \%$ ). 

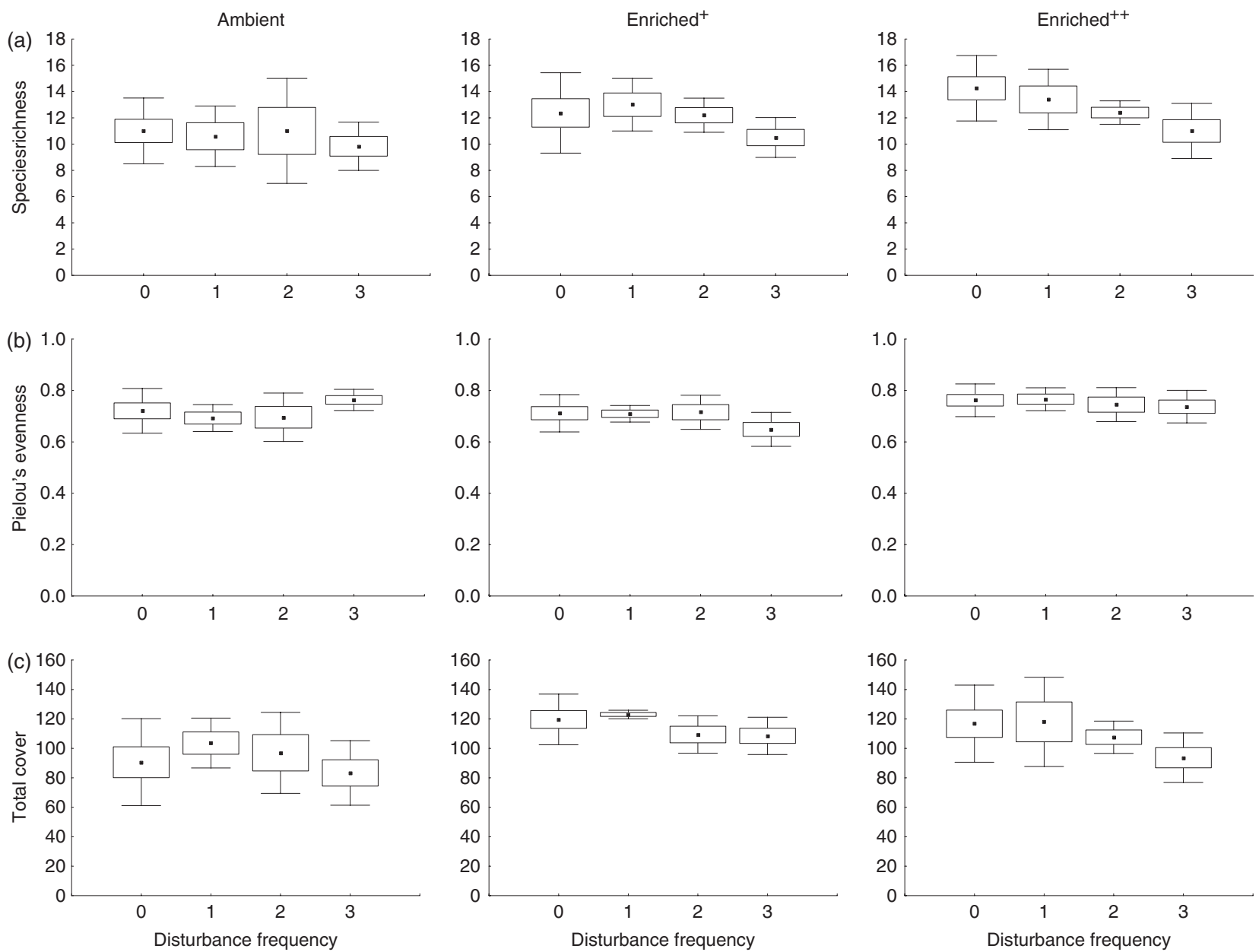

Fig. 3. Influence of disturbance frequency on (a) species richness, (b) Pielou's evenness and (c) total cover at the different nutrient levels after 9 weeks of experimental duration. Mean values ), standard errors (box) and standard deviations (whisker) are indicated. Disturbance level $0=$ controls (no disturbance); level 1 = disturbed once after 8 weeks; level $2=$ disturbed every 4 weeks; level $3=$ disturbed every 2 weeks.

Rare species (mean cover $<1 \%$ ) included eight macroalgae and 11 macroinvertebrates. The richness of fouling communities, including the unaffected controls, varied between 7 and 17 species (Fig. 3a) and was therefore, on average, higher than recorded after the 9 weeks that preceded the experiment when 4 to 11 species were found on the panels. Values for the Pielou's evenness of all communities spatially varied between 0.54 and 0.85 (Fig. 3b), suggesting that species proportions in the communities were medium to highly equal, with a relative low dominance of individual species (Magurran 1988). Additionally, total percent cover of fouling communities through all nutrient levels ranged from 53\% to $154 \%$ (Fig. 3c) showing that there was space available in several of the experimental units for new settlers. This reflects direct effects of the disturbance applied and the absence of competitive exclusion.
Effects of disturbance and nutrient availability on fouling community diversity

After 9 weeks of experimental manipulation, no interactive effects of 'nutrient availability' and 'disturbance frequency' on species richness were indicated by ANOVA (Table 3). No significant relationship between species richness and disturbance frequency was observed at the ambient and enriched ${ }^{+}$nutrient levels (Table 4), while a significant negative linear relationship between the two factors was detected at the highest level of nutrient supply $\left(R^{2}=0.298, P<0.01\right.$, Fig. 4). Under these enriched ${ }^{++}$ conditions, the red algae Jania sp., Corallina sp. and the green alga Ulva rigida were present at low disturbance frequencies but became extinct with increasing disturbance frequency. Accordingly, ANOVA detected a significant effect of disturbance on species richness (Table 3). 
Table 3. Effects of nutrient availability and disturbance frequency on diversity and total cover after 9 weeks of experimental duration (3factorial nested ANOVA).

\begin{tabular}{|c|c|c|c|c|c|}
\hline Diversity measure & source & df & MS & $\mathrm{F}$ & P-value \\
\hline \multirow[t]{6}{*}{ species richness } & $\mathrm{N}$ & 2 & 21.52 & 2.99 & 0.100 \\
\hline & $\mathrm{B}(\mathrm{N})$ & 9 & 7.18 & 1.28 & 0.302 \\
\hline & D & 3 & 12.63 & 3.53 & $0.028 *$ \\
\hline & $N \times D$ & 6 & 4.79 & 1.34 & 0.273 \\
\hline & $\mathrm{D} \times \mathrm{B}(\mathrm{N})$ & 27 & 3.57 & 0.64 & 0.860 \\
\hline & residual & 20 & 5.57 & & \\
\hline \multirow[t]{6}{*}{ Pielou's evenness } & $\mathrm{N}$ & 2 & 0.01 & 2.64 & 0.125 \\
\hline & $\mathrm{B}(\mathrm{N})$ & 9 & 0.01 & 1.79 & 0.132 \\
\hline & D & 3 & 0.00 & 0.13 & 0.942 \\
\hline & $N \times D$ & 6 & 0.00 & 1.39 & 0.254 \\
\hline & $\mathrm{D} \times \mathrm{B}(\mathrm{N})$ & 27 & 0.00 & 1.16 & 0.368 \\
\hline & residual & 20 & 0.00 & & \\
\hline \multirow[t]{6}{*}{ Simpson index } & $\mathrm{N}$ & 2 & 0.01 & 2.59 & 0.129 \\
\hline & $\mathrm{B}(\mathrm{N})$ & 9 & 0.00 & 1.66 & 0.164 \\
\hline & $\mathrm{D}$ & 3 & 0.00 & 1.03 & 0.397 \\
\hline & $N \times D$ & 6 & 0.00 & 1.34 & 0.276 \\
\hline & $\mathrm{D} \times \mathrm{B}(\mathrm{N})$ & 27 & 0.00 & 1.19 & 0.346 \\
\hline & residual & 20 & 0.00 & & \\
\hline \multirow[t]{6}{*}{ total \% cover } & $\mathrm{N}$ & 2 & 1637.25 & 2.60 & 0.128 \\
\hline & $\mathrm{B}(\mathrm{N})$ & 9 & 629.24 & 1.28 & 0.308 \\
\hline & $\mathrm{D}$ & 3 & 731.73 & 2.27 & 0.103 \\
\hline & $\mathrm{N} \times \mathrm{D}$ & 6 & 110.92 & 0.34 & 0.906 \\
\hline & $\mathrm{D} \times \mathrm{B}(\mathrm{N})$ & 27 & 321.84 & 0.65 & 0.851 \\
\hline & residual & 20 & 493.10 & & \\
\hline
\end{tabular}

$\mathrm{df}=$ degrees of freedom; $\mathrm{MS}=$ mean square; $\mathrm{N}=$ nutrient availability; $\mathrm{B}(\mathrm{N})=$ block nested in nutrient availability; $\mathrm{D}=$ disturbance .

*Statistical significance $(P<0.05)$.

Although post-hoc testing (Tukey's HSD; $\mathrm{P} \leq 0.05$ ) identified no differences between disturbance levels, visual inspection of graph led to assume that richness was significantly different between the two extreme ends of the disturbance gradient (Fig. 3a).

In the undisturbed communities, nutrient enrichment enhanced species richness (Fig. 5; ANOVA: $\mathrm{F}=3.810$; $\mathrm{P}=0.038$ ) with more macroalgae species establishing under higher mineral nutriment supply. Mean algal richness was higher at level enriched ${ }^{+}$and enriched ${ }^{++}$than in the controls (Bonferroni test; $\mathrm{P}<0.05$ ). On average, two

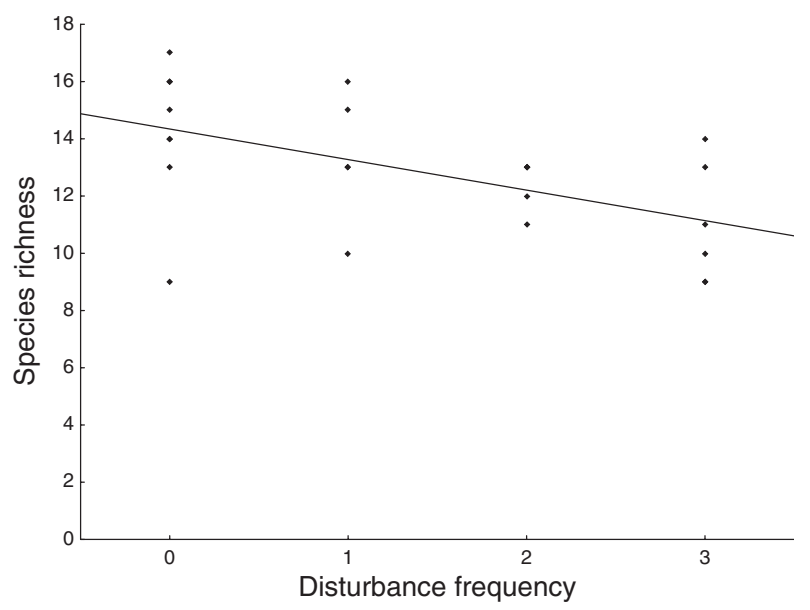

Fig. 4. Relationship between disturbance frequency and species richness at the highest level of nutrient supply. Disturbance level $0=$ controls (no disturbance); levels 1-3 correspond to one disturbance every 8,4 and 2 weeks respectively.

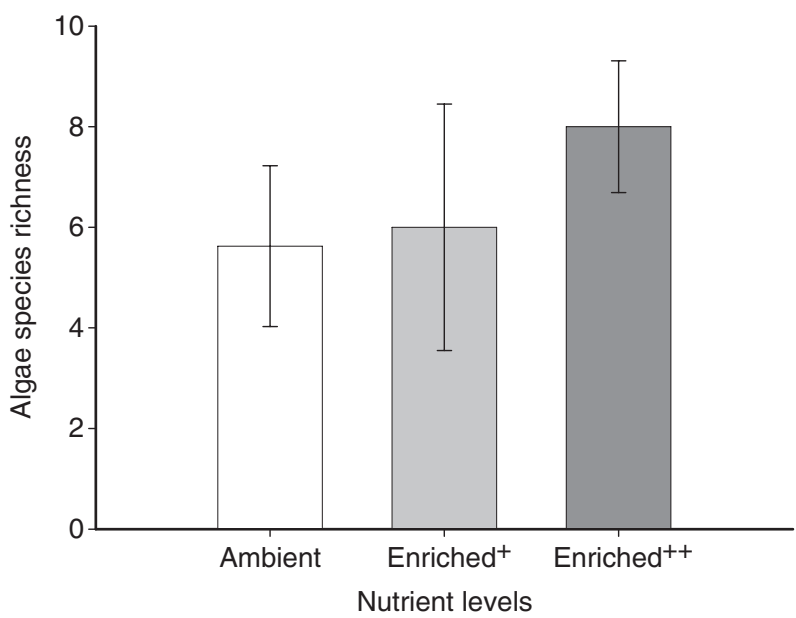

Fig. 5. Algal species richness of the undisturbed communities at the different nutrient levels: ambient (white), enriched ${ }^{+}$(light grey) and enriched $^{++}$(dark grey). Mean values (bars) and standard deviations (whiskers) are indicated. $\mathrm{n}=8$.

Table 4. Effects of disturbance on diversity and total cover after 9 weeks of experimental duration.

\begin{tabular}{|c|c|c|c|c|c|c|c|c|}
\hline \multirow{2}{*}{$\begin{array}{l}\text { Nutrient } \\
\text { availability }\end{array}$} & \multicolumn{2}{|c|}{ species richness } & \multicolumn{2}{|c|}{ Pielou's evenness } & \multicolumn{2}{|c|}{ Simpson index } & \multicolumn{2}{|c|}{ total \% cover } \\
\hline & $R^{2}$ & P-value & $R^{2}$ & P-value & $R^{2}$ & P-value & $R^{2}$ & P-value \\
\hline ambient & 0.022 & 0.488 & 0.035 & 0.378 & 0.039 & 0.352 & 0.012 & 0.608 \\
\hline enriched $^{+}$ & 0.099 & 0.134 & 0.107 & 0.118 & 0.081 & 0.178 & 0.144 & 0.068 \\
\hline enriched $^{++}$ & 0.298 & $0.006^{*}$ & 0.036 & 0.374 & 0.151 & 0.061 & 0.154 & 0.058 \\
\hline
\end{tabular}

Results of the linear regression analyses are shown for each nutrient level.

*Statistical significance $(P<0.01)$. 
more algal species were present in the assemblages that experienced the nutrient level enriched ${ }^{++}$than in the control communities, namely the red algae Jania sp. and Corallina sp.

Pielou's evenness and Simpson index were affected neither by the applied nutrient concentrations nor by the disturbance treatments (Tables 3 and 4). No interactive effects of 'nutrient availability' and 'disturbance frequency' on either variable were identified.

\section{Discussion}

Our nutrient enrichment was equivalent to a 'site fertility' treatment because the community was algal-dominated. Fertilization enhanced community diversity by favouring the establishment and growth of macroalgal species, which were absent from the low-nutrient panels. As the study site is oligotrophic (Caldeira et al. 2002) adding nutrients may reduce the effect of a limiting factor.

We additionally found a significant negative linear relationship between the applied physical disturbance and species richness at the highest level of nutrient enrichment. This negative influence on richness traces back to the extinction of three macroalgae species under conditions of frequently occurring disturbances. A linear negative disturbance-diversity relationship under enhanced levels of productivity at first sight contradicts the predictions of Kondoh (2001). This concept emphasizes that an increase in productivity influences the colonization rates of all species, in particular of the competitively dominant species while disturbance should decrease competitive dominance and, consequently, competitive exclusion. In our case, the highest nutrient concentrations facilitated the recruitment of Jania sp. and Corallina sp., which turned out to be the most sensitive to disturbance. It should be stressed that the panels were not protected from natural disturbance such as predation. In this oligotrophic environment, the lack of nutrients seems to constitute a stress. This is illustrated by the rise in species richness when this stressor is alleviated by the experimental addition of nutrients. Thus, in our system, we are dealing with 2 factors: nutrients and disturbance, which at one end of their gradients constitute a stress for the community. According to Vinebrooke et al. (2004), the diversity of a community should decrease with the progressive addition of stressors when species' sensitivity to different stressors correlates directly or when the exposure to one stressor enhances the sensitivity to a second stressor. This seems to be the case for some of the macroalgal species encountered in this experiment. At the naturally oligotrophic state (low-nutrient stress), they apparently recruit or grow too slowly to be able to establish in the community. At enriched ${ }^{++}$conditions, they do establish, but apparently still grow too slowly to be able to compensate for the biomass loss inflicted by strong disturbance. Consequently, the multiple-stressor model of Vinebrooke et al. (2004) explains our findings better than the productivity-disturbance model by Kondoh (2001). The latter does not apply, presumably because at natural and at enhanced productivity, this oligotrophic system is too slow to become truly competitive within 18 weeks, the duration of this experiment. Using similar experimental setups, Jara et al. (2006) and Svensson et al. (2007) also investigated interacting effects between disturbance and productivity in fouling communities in Brazil and West Sweden, respectively. In contrast to our study, they allowed 12 weeks for pre-experiment establishment and subsequently manipulated for 24 weeks. Also, the resolution of the disturbance regime with seven levels was wider than in our study: no disturbance and disturbed every second, fourth, sixth, eighth, 10th and 12th week (Jara et al. 2006; Svensson et al. 2007). In an oligotrophic study site in Brazil, Jara et al. (2006) proved that diversity and species richness peaked at intermediate levels of disturbance and that, like in our study, nutrient enrichment increased total species richness and algal species richness in particular. Moreover, interactive effects of disturbance and productivity on species richness were also detected but only partially supported by Kondoh's model. At ambient (i.e. low) nutrient concentrations, species richness linearly decreased with increasing disturbance, as predicted by Kondoh's model, but a unimodal and positive disturbance-diversity relationship was not found at intermediate and high nutrient concentrations, respectively (Jara et al. 2006). Svensson et al. (2007) also observed maximum species number at an intermediate frequency of disturbance in western Sweden. Nevertheless, the relationship between disturbance and diversity was not affected by the nutrient treatments (Svensson et al. 2007). Our study is a first account on the interplay between disturbance and productivity on early successional fouling assemblages. The mechanisms producing this pattern are complex and site-specific.

A combination of local factors presumably prevented the emergence of unimodal disturbance-richness or productivity-richness patterns in our study, which are prerequisites for the Kondoh model. We hardly observed effects of disturbance on species numbers at medium and low nutrient levels. We had expected that the high number of rare species would lead to more pronounced effects of the disturbances, as the chance to eliminate the entire population of a rare species should be relatively high when removing the complete biomass from $20 \%$ of the substrate. In our system, the number of species which colonized the opened patches after a disturbance usually balanced the losses (J. Canning-Clode, personal 
observations). Consequently, the net effect of disturbances on species richness under ambient or close-to-ambient nutrient conditions in our systems was negligible. The effects of the disturbance regimes on the dominant species were generally moderate too. Two of the abundant forms were colonial organisms, i.e. Diplosoma sp. and Lithophyllum incrustans, which are capable of lateral growth. These re-invaded the opened patches from the margins (J. Canning-Clode, personal observations) dampening any effects on evenness. However, because of the generally slow growth of organisms in the oligotrophic system, they did not monopolize the opened space to prevent other larvae and spores to settle. It is assumed that in spring and summer, the pool of colonizers in Madeiran waters is relatively homogenous, at least with regard to the number of species present, although no data about temporal and spatial patterns in propagule supply are available for this sea area yet.

The general weakness of treatment effects in this study is surprising, as both factors, disturbance and nutrient availability are widely considered to affect competitive hierarchies and thus shape community structure (Krebs 2001; Roxburgh et al. 2004). By the end of the experiment, the communities were 18 weeks old and, because of slow individual growth in the oligotrophic environment, the fouling communities in this study were not (yet) fully driven by inter-specific competition. This is documented by the facts that empty space was still available on almost all settlement panels after 18 weeks. Furthermore, even in undisturbed assemblages, no species were excluded during the course of the experiment. Enhancing nutrient concentrations should intensify competition in all benthic systems in which macroalgae are present and this should ultimately decrease diversity (Huston 1979; Tilman 1988). However, in the very oligotrophic Madeiran coastal waters, substratum was not fully occupied and competition probably moderate. Under these conditions nutrient enrichment increased diversity by allowing further species to establish. Consequently, our results do not contradict the Kondoh model but rather confirm the multiple-stressor model (Vinebrooke et al. 2004). Similar system-specific factors may have modulated the diversity-disturbance relationship in other studies. In a recent review, Mackey \& Currie (2001) examined 85 studies on the diversity-disturbance relationships published between 1985 and 1996 and they found that these relationships do not consistently show the predicted peaked pattern. In their review, approximately $21 \%$ of the examined studies revealed a negative linear relationship between disturbance and species richness (Mackey \& Currie 2001). Therefore, the role of disturbance as a mechanism to maintain species co-existence seems to be more system-specific than proposed in the past.

\section{Acknowledgements}

We are grateful to the Natural Park of Madeira and the Marine Biology Station of Funchal for the logistic support during the field work. We are thankful to Peter Wirtz and Sara Ferreira for their help with species identification. People too numerous to mention assisted in the field work. Their help is appreciated. We thank two anonymous reviewers for helpful criticism and suggestions that significantly improved the early version of this manuscript. The fertilizer Plantacote ${ }^{\circledR}$ pluss $6 \mathrm{M}$ was provided by Aglukon GmbH. This study was part of the international training and research program GAME, funded by the Mercator Foundation. J. Canning-Clode studies were supported by a Fellowship from the German Academic Exchange Service (DAAD). This is contribution number 11 from Marine Biology Station of Funchal.

\section{References}

Allcock K.G., Hik D.S. (2003) What determines disturbanceproductivity-diversity relationships? The effect of scale, species and environment on richness patterns in an Australian woodland. Oikos, 102, 173-185.

Balvanera P., Pfisterer A.B., Buchmann N., He J.S., Nakashizuka T., Raffaelli D., Schmid B. (2006) Quantifying the evidence for biodiversity effects on ecosystem functioning and services. Ecology Letters, 9, 1146-1156.

Benedetti-Cecchi L. (2004) Experimental design and hypothesis testing in ecology. In: Gambi M.C., Dappiano M. (Eds), Mediterranean Marine Benthos: A Manual of Methods for its Sampling and Study, Biologia Marina Mediterranea 11 (Suppl. 1), 407-455.

Berendse F. (1993) Ecosystem stability, competition and nutrient cycling. In: Schlulze E.-D., Mooney H.A. (Eds), Biodiversity and Ecosystem Function. Ecological Studies, 99: 409-431. Springer Verlag, Heidelberg.

Caldeira R.M.A., Groom S., Miller P., Pilgrim D., Nezlin N.P. (2002) Sea-surface signatures of the island mass effect phenomena around Madeira Island, Northeast Atlantic. Remote Sensing of Environment, 80, 336-360.

Chalcraft D.R., Williams J.W., Smith M.D., Willig M.R. (2004) Scale dependence in the species-richness-productivity relationship: The role of species turnover. Ecology, 85, 2701-2708.

Chase J.M., Leibold M.A. (2002) Spatial scale dictates the productivity-biodiversity relationship. Nature, 416, 427-430.

Chase J.M., Leibold M.A., Downing A.L., Shurin J.B. (2000) The effects of productivity, herbivory, and plant species turnover in grassland food webs. Ecology, 81, 2485-2497.

Connell J.H. (1978) Diversity in tropical rain forests and coral reefs: high diversity of trees and corals is maintained only in a non-equilibrium state. Science, 199, 1302-1310. 
Fukami T., Morin P.J. (2003) Productivity-biodiversity relationships depend on the history of community assembly. Nature, 424, 423-426.

Gessner M.O., Inchausti P., Persson L., Raffaelli D.G., Giller P.S. (2004) Biodiversity effects on ecosystem functioning: insights from aquatic systems. Oikos, 104, 419-422.

Giller P.S., Hillebrand H., Berninger U.G., Gessner M.O., Hawkins S., Inchausti P., Inglis C., Leslie H., Malmqvist B., Monaghan M.T., Morin P.J., O’Mullan G. (2004) Biodiversity effects on ecosystem functioning: emerging issues and their experimental test in aquatic environments. Oikos, 104, 423-436.

Grasshoff K., Kremling K., Ehrhardt M. (1999) Methods of Seawater Analysis. Wiley-VCH, Weinheim.

Grime J.P. (1977) Evidence for the existence of three primary strategies in plants and its relevance to ecological and evolutionary theory. The American Naturalist, 111, 1169-1194.

Hooper D.U., Chapin F.S., Ewel J.J., Hector A., Inchausti P., Lavorel S., Lawton J.H., Lodge D.M., Loreau M., Naeem S., Schmid B., Setala H., Symstad A., Vandermeer J.J., Wardle D.A. (2005) Effects of biodiversity on ecosystem functioning: a consensus of current knowledge. Ecological Monographs, 75(1), 3-35.

Hubbell S.P. (2001) The Unified Neutral Theory of Biodiversity and Biogeography. Princeton University Press, Princeton, NJ, USA.

Huston M.A. (1979) A general hypothesis of species diversity. The American Naturalist, 113, 81-101.

Huston M. (1994) Biological Diversity: The Coexistence of Species on Changing Landscapes. Cambridge University Press, New York.

Jara V.C., Miyamoto J.H.S., da Gama B.A.P., Molis M., Wahl M., Pereira R.C. (2006) Limited evidence of interactive disturbance and nutrient effects on the diversity of macrobenthic assemblages. Marine Ecology Progress Series, 308, 37-48.

Jeffrey S.W., Humphrey G.F. (1975) New spectrophotometric equations for determining chlorophylls a, b, c1 and c2 in higher-plants, algae and natural phytoplankton. Biochemie und Physiologie der Pflanzen, 167, 191-194.

Kondoh M. (2001) Unifying the relationships of species richness to productivity and disturbance. Proceedings of the Royal Society of London. Series B, 268, 269-271.

Krebs C.J. (2001) Ecology, the Experimental Analysis of Distribution and Abundance. Benjamin Cummings, San Francisco.

Lalli C.M., Parsons T.M. (1997) Biological Oceanography: An Introduction. Butterworth-Heinemann, Oxford.

Loreau M., Naeem S., Inchausti P., Bengtsson J., Grime J.P., Hector A., Hooper D.U., Huston M.A., Raffaelli D., Schmid B., Tilman D., Wardle D.A. (2001) Ecology - Biodiversity and ecosystem functioning: current knowledge and future challenges. Science, 294, 804-808.

Mackey R.L., Currie D.J. (2001) The diversity-disturbance relationship: is it generally strong and peaked? Ecology, 82, 3479-3492.
Magurran A. (1988) Ecological Diversity and its Measurement. Princeton University Press, Princeton, NJ.

Menge B.A., Sutherland J.P. (1987) Community regulation variation in disturbance, competition, and predation in relation to environmental-stress and recruitment. The American Naturalist, 130, 730-757.

Mittelbach G.G., Steiner C.F., Scheiner S.M., Gross K.L., Reynolds H.L., Waide R.B., Willig M.R., Dodson S.I., Gough L. (2001) What is the observed relationship between species richness and productivity? Ecology, 82, 2381-2396.

Proulx M., Mazumder A. (1998) Reversal of grazing impact on plant species richness in nutrient-poor vs. nutrient rich ecosystems. Ecology, 79, 2581-2592.

Roxburgh S., Shea K., Wilson J. (2004) The intermediate disturbance hypothesis: patch dynamics and mechanisms of species coexistence. Ecology, 85, 359-371.

Sala E., Knowlton N. (2006) Global marine biodiversity trends. Annual Review of Environment and Resources, 31, 93-122.

Sousa W.P. (1979) Disturbance in marine intertial boulder fields: non-equilibrium maintenance of species diversity. Ecology, 60, 1225-1239.

Sousa W.P. (1984) The role of disturbance in natural communities. Annual Review of Ecology and Systematics, 15, 353-391.

Svensson J.R., Lindegarth M., Siccha M., Lenz M., Molis M., Wahl M., Pavia H. (2007) Maximum species richness at intermediate frequencies of disturbance: consistency among levels of productivity. Ecology, 88, 830-838.

Tilman D. (1988) Plant Strategies and the Dynamics and Structure of Plant Communities. Princeton University Press, Princeton.

Underwood A.J. (1997) Experiments in Ecology: Their Logical Design and Interpretation Using Analysis of Variance. Cambridge University Press, Cambridge.

Vinebrooke R.D., Cottingham K.L., Norberg J., Scheffer M., Dodson S.I., Maberly S.C., Sommer U. (2004) Impacts of multiple stressors on biodiversity and ecosystem functioning: the role of species co-tolerance. Oikos, 104, 451-457.

Waide R.B., Willig M.R., Steiner C.F., Mittelbach G., Gough L., Dodson S.I., Juday G.P., Parmenter R. (1999) The relationship between productivity and species richness. Annual Review of Ecology and Systematics, 30, 257-300.

White P.S., Pickett S.T.A. (1985) Natural disturbance and patch dynamics: an introduction. In: Pickett S.T.A., White P.S. (Eds), The Ecology of Natural Disturbance and Patch Dynamics. Academic Press, Orlando: 3-13.

Worm B., Duffy J.E. (2003) Biodiversity, productivity and stability in real food webs. Trends in Ecology \& Evolution, 18, 628-632.

Worm B., Reusch T., Lotze H. (2000) In situ nutrient enrichment: Methods for marine benthic ecology. International Review of Hydrobiology, 85, 359-375. 